\title{
Metabolic and Clinical responses to Bunium Persicum (Black Caraway) supplementation in overweight and obese patients with type 2 diabetes: a double-blind randomized placebo-controlled clinical trial
}

\section{Saber Jafari-Maskouni}

Zahedan University of Medical Sciences

\section{Mansour Shahraki}

Zahedan University of Medical Sciences

Milad Daneshi-Maskooni ( $\square$ miladdaneshi@gmail.com )

Tehran University of Medical Sciences, School of Nutritional Sciences and Dietetics

https://orcid.org/0000-0003-1373-1358

Alireza Dashipour

Zahedan University of Medical Sciences

Ali Shamsi-Goushki

Zahedan University of Medical Sciences

Zinat Mortazavi

Zahedan University of Medical Sciences

Research

Keywords: Type 2 diabetes, Bunium Persicum, Glucose indices, Lipids, Nesfatin-1

Posted Date: May 11th, 2020

DOI: https://doi.org/10.21203/rs.2.21917/v2

License: (c) (i) This work is licensed under a Creative Commons Attribution 4.0 International License. Read Full License

Version of Record: A version of this preprint was published on August 26th, 2020. See the published version at https://doi.org/10.1186/s12986-020-00494-4. 


\section{Abstract}

Background : Diabetes mellitus is the most common metabolic disorder worldwide. We aimed to determine the effects of Bunium Persicum (BP) on serum glucose indices, lipid profile, and nesfatin-1 levels in overweight or obese T2DM patients.

Methods : Participant recruitment took place in the diabetic clinic of Bu-Ali hospital in Zahedan. Based on the eligibility criteria, 60 participants were randomly divided into two groups, namely BP $(n=30)$ and placebo $(n=30)$. The supplementation was one $1000 \mathrm{mg}$ capsule 2 times / day BP with meals (lunch and dinner) for 8 weeks. Bodyweight, waist circumference, serum nesfatin-1, fasting blood sugar (FBS) and insulin (FBI), total cholesterol (TC), triglyceride (TG), low-density lipoprotein cholesterol (LDL-C), and highdensity lipoprotein cholesterol (HDL-C) were measured. Quantitative insulin sensitivity checks index (QUICKI), homeostasis model assessment-insulin resistance (HOMA-IR) and Body Mass Index (BMI) were also calculated.

Results : In comparison with placebo, BP significantly decreased FBS, HOMA-IR, and BMI $(P<0.05)$. The differences in the FBI, QUICKI, TG, TC, LDL, HDL,WC and Nesfatin-1 were not significant $(P>0.05)$.

Conclusion : BP supplement improved serum glucose indices and decreased BMI among overweight or obese T2DM patients; though, further trials are suggested to confirm results.

Trial Registration : Iranian Registry of Clinical Trials (IRCT), IRCT20181207041876N1, Registered 18/01/2019, https://irct.ir/trial/35752

\section{Background}

Diabetes is a multifactorial autoimmune disorder, which is determined by a high blood glucose level. The prevalence of diabetes mellitus type 2 (T2DM) is increasing globally and its complications are a major health problem ${ }^{(1,2)}$. In 2014, over 422 million had diabetes and a continuous rise in DM prevalence is expected ${ }^{(3)}$.

Being overweight, obesity, impaired blood glucose and hyperlipidemia are some risk factors of T2DM (4, 5). Some metabolic perturbations such as B-cell dysfunction, impaired insulin secretion, insulin resistance, and dyslipidemia contribute to the pathogenesis of diabetes ${ }^{(6)}$.

Adipose tissue is an active endocrine organ which produces adipokines that control many physiological functions such as immunity, inflammation and energy homeostasis ${ }^{(7)}$. Nesfatin- 1 is one of these adipokines that is involved in appetite regulation and body fat storage by participating in important functions in metabolizing glucose, phosphorylation specific signaling proteins, and increasing liver insulin sensitivity, specifically by AMP-activated protein kinase ${ }^{(8,9)}$. This adipokine is expressed in parts of the brain that interfere with metabolism regulation and dietary behavior ${ }^{(10)}$. Nesfatin gene expression is activated by peroxisome proliferator-activated receptors (PPARs), especially PPARy ${ }^{(11,12)}$. Nesfatin-1 
can decrease food intake when administered into the third cerebral ventricle of rats ${ }^{(13)}$. Nesfatin-1 can decrease food intake when administered into the third cerebral ventricle of rats. Fasting blood nesfatin-1 was significantly decreased in T2DM patients compared to healthy subjects and might be one of the appetite-related hormones involved in diabetic Polyphagia(14).

Management of diabetes to prevent complexity include changes in dietary patterns, regular physical activity, and anti-diabetic medications $(15,16)$.

Various types of traditional, complementary or alternative therapies have been increasingly used for the treatment of diabetes in human and animal models of type 2 diabetes ${ }^{(17)}$. Herbal medicines are a major part of these therapies ${ }^{(18)}$. One of the medicinal plants is Bunium Persicum (Black Caraway). Bunium Persicum, which belongs to the Apiaceae family and is generally known in Iran as 'Zireh Siah' has always been used in traditional Iranian medicine for certain disorders $(19,20)$. The main constituents of BP, that have been demonstrated in recent studies, are cumin aldehyde, caffeic acid, p-coumaric acid, gammaterpinene, p-cymene, cuminal, flavonoids (such as quercetin and kaempferol) and a high level of polyphenols compound ${ }^{(21-25)}$. The reported effects of cumin aldehyde one of the most studied agent, include the inhibition of aldose reductase and r-Glucosidase, the insulinotropic and b cell-protective action, anti-obesity and liver protective effect ${ }^{(26-29)}$.

According to the data available, the results of previous studies on the effect of Bunium Persicum (black caraway) on T2DM patients and normal subjects were inconsistent. Some previous animal and human studies found that caraway intake could improve lipid profiles and decrease blood glucose concentrations $(30,31)$. However, Ghorbani et al. reported that caraway supplementation had no beneficial effects on fasting blood glucose concentrations and some other researchers revealed no significant effect of caraway intake on lipid profiles and fasting blood glucose ${ }^{(31,32)}$.

Furthermore, evidence has suggested that Bunium Persicum and Carum Carvi are plant members of the Apiaceae family and have similar active ingredients $(33,34)$. In addition, slimming, appetite-suppressing, hypoglycemic and antihyperlipidemic effects of Carum Carvi have been shown in recent studies $(35,36)$. With regard to the food intake decreasing effects of nesfatin-1 shown in previous studies (37), we hypothesized that Bunium Persicum can suppress appetite and reduce food intake by increasing levels of nesfatin-1 that can in turn lead to the decrease of blood sugar and lipid profiles. However, no human studies have been carried out to determine the effect of BP on T2DM and nesfatin-1 in overweight or obese T2DM patients and requires further investigation. This trial was designed to assess the metabolic and clinical responses to Bunium Persicum (Black Caraway) supplementation in overweight and obese patients with type 2 diabetes.

\section{Methods}

\section{Ethical Considerations}


The ethics committee of Zahedan University of Medical Sciences approved this double-blind randomized placebo-controlled clinical trial under the code; IR.ZAUMS.REC.1397.332. The present study was registered in the Iranian Registry of Clinical Trials; IRCT20181207041876N1 on 18/01/2019. The participants were overweight or obese T2DM patients who had referred to the diabetic clinic of Bu-Ali Hospital of Zahedan. This trial lasted from 23 June 2019 until 22 October 2019.

An informed written consent form was obtained from the subjects before data collection. Participants were informed at the outset of the study about risks and possible side effects of BP, blood sampling, the confidentiality of participants' personal information, right to withdraw from the study at any point, free-ofcharge participation in the trial, weekly contact by the researcher to participants, and the approval section.

\section{-Study Design and Subjects:}

This double-blind, randomized, placebo-controlled clinical trial was carried out on 60 overweight or obese patients with T2DM who were randomly divided into two groups (Placebo group [ $n=30]$ and Bunuim Persicum Group [ $\mathrm{n}=30]$ ) by the block randomization method.

Selected patients took Bunuim Persicum and Placebo capsules for 8 weeks. The packaging. of supplements and capsules were similar in appearance. The researchers and subjects were blinded to group assignment and capsule content until the end of the analysis.

Inclusion criteria were T2DM diagnosed, use of oral hypoglycemic drugs, age 30-65 years, and $25 \leq \mathrm{BMl}<40 \mathrm{~kg} / \mathrm{m}^{2}$. Exclusion criteria were suffering from cognitive disease or other psychotic illnesses, depression, acute systemic disease, cystic fibrosis disease, muscular dystrophy, protein malnutrition, a history of gastrointestinal surgery, neurological disorders, structural abnormalities of the gastrointestinal tract, disability, uncontrolled hypertension $(>140 / 90 \mathrm{mmHg})$, antihypertensive, probiotics, multivitaminmineral and antioxidant supplements during the three past months, pregnancy or lactation, expert athlete, intake of statins, caraway interacting drugs, alcohol, cigarette, and drug abuse, losing weight during the past 3-months, changing the type and dose of T2DM medications, and not taking more than $10 \%$ of the intervention supplement.

This trial adhered to CONSORT guidelines and included a completed CONSORT checklist as an additional file.

\section{-Randomization and Intervention:}

According to the block randomization method, participants were divided into two equal groups by an assistant (BP [n=30] or placebo [n=30] groups). The stratified randomization method was used for age and gender. The ratio of the two groups was 1:1. Three patients from the BP group and 2 patients from the placebo group declined to participate after randomization and before the beginning of the study (Figure 1). 
The blinding of intervention allocation was done for both the participants and researchers as $A$ and $B$ packages. The BP and placebo capsules were made by the Herbarium center of the Kerman Faculty of Pharmacy, Kerman University of Medical Sciences, Kerman, Iran. The shape, size, and color of the capsules were similar. The contents of capsules were $1 \mathrm{gr}$ of whole BP or Starch powder. Before supplementation, the capsules were placed alongside each other for one week for their smell to rub off on each other. The absorbed Bunium Persicum volatile oil in the placebo capsules was very low to be able to change health parameters. According to a similar previous study that investigated the effect of cumin (one of the Apiaceae family plants) on overweight and obese women, the dose of supplements was determined at 2 grams per day or 2 capsules per day, taken with meals (twice a day with lunch and dinner) ${ }^{(38)}$. However, the intake and absorption of the BP either with or without food should be investigated further. The supplements were distributed on a monthly basis and the checking of compliance status was also done monthly face to face and weekly over the telephone. The duration of the intervention period was 8 weeks.

The BP voucher number was Bunium Persicum (Boiss) B. Fedtch, Family: Apiaceae, KF1141-1. The analysis of the whole BP was performed by the Herbarium center of the Kerman Faculty of Pharmacy, Kerman University of Medical Sciences, Kerman, Iran. The contents of Bunium Persicum essential oil according to the gas chromatography-mass spectrometry (GC-MS) was $46.1 \%$ Y-Terpinene and $15.5 \%$ cumin aldehyde.

\section{-Assessments and Measurements:}

\section{General Characteristics, Dietary Intakes, and Physical Activity.}

The T2DM patients were identified, the eligibility criteria checked, the study details were clarified, and informed consent was obtained by the main investigator (BSC student). The questionnaires including the general questionnaire, 24-hour food recall (at the beginning and end), and short-form IPAQ (SF-IPAQ) questionnaire (at the beginning and end) were administered through interviewing.

The dietary status was determined using gram per day of values from 24-hour food recall (valid in Iran $\left.{ }^{(39)}\right)$ by the Nutritionist 4 software ${ }^{(39,40)}$.

The IPAQ questionnaire provides information on physical activity that people do as part of their everyday lives. The questions are about the time when the person has been active during the last 7 days. This questionnaire addresses the activities in the workplace or as part of the homework and the garden, place to place movement, exercises, and leisure activities. It also considers all the intense activities over the past 7 days. Intense activities require a great deal of physical power and more intense breathing. The IPAQ addresses only continuous activities for at least 10 minutes. Its short-form has 7 classified questions determining the three activity levels (1-3 or low-to-high levels). This questionnaire had been validated in Iran ${ }^{(41,42)}$.

\section{Anthropometric measurements.}


Weight (at the beginning and end), height (at the beginning) and waist circumference (at the beginning and end) were determined by using a digital scale and stadiometer (Seca ${ }^{\circledR}$ Germany, Model: 755 1021994). They were measured as such: Weight without shoes, with minimal clothing, and with 100-gram accuracy; height without shoes, standing, heels sticking to the wall, flat and forward head, and with 0.5centimeter accuracy; and waist circumference with minimal clothing, at the middle of the last rib and the iliac crest. Body mass index (BMI) was calculated via dividing weight in kilograms by squared height in meters.

\section{Blood biomarkers measurement.}

At the beginning and the end of the study, $10 \mathrm{ml}$ of blood (at the beginning and end) was taken from the peripheral vein after 12-hour fasting during the night and centrifuged for $20 \mathrm{~min}$ (3000 $\mathrm{g}$ ). Serum glucose was determined on the same day of blood withdrawal. The remaining serums $(5 \mathrm{ml})$ were frozen and stored at $-80^{\circ} \mathrm{C}$ up to the analysis.

Serum nesfatin was determined using the sandwich ELISA and kit as Shanghai Crystal Day Biotech Co. $\mathrm{Ltd}^{\circledR}$; Intra-assay $\mathrm{CV}<8 \%$, Inter-assay $\mathrm{CV}<10 \%$ by an automatic device (Elisys Uno Human ${ }^{\circledR}$ ). Similarly, the ELISA kit for insulin was diametra ${ }^{\circledR}$ Co of Italy, DCM076-8; Intra-assay CV $\leq 5 \%$, Inter-assay CV $\leq 10 \%$. Serum glucose was measured according to the glucose oxidase method using the Hitachi analyzer device $\left(q 17^{\circledR}\right)$ and the specific kit as Bionik ${ }^{\circledR}$, Liquid Stable, Glucose oxidase GOD-POD, Mono-reagent; Intraassay $\mathrm{CV} \leq 2.10 \%$, Inter-assay $\mathrm{CV} \leq 3.09 \%$. Also, the serum levels of TC, TG, LDL-C, and HDL-C were measured using Hitachi analyzer device $\left(q 17^{\circledR}\right)$ and the specific kits as 1-Bionik ${ }^{\circledR}$, Liquid Stable, Enzymatic Colorimetric CHOD-POD, 2-Bionik ${ }^{\circledR}$, Liquid Stable, GPO-POD, Mono-reagent, 3-Bionik ${ }^{\circledR}$, Liquid Stable, Direct. Enzymatic Colorimetric, and 4-Bionik ${ }^{\circledR}$, Liquid Stable, Direct. Enzymatic Colorimetric, respectively. The intra- and inter-assay coefficients of variation for TC, TG, LDL-C, and HDL-C were $\leq 1.216 \%$ and $\leq 6.906 \%, \leq 1.573 \%$ and $\leq 7.704 \%, \leq 1.76 \%$ and $\leq 0.65 \%$, and $\leq 0.7 \%$ and $\leq 1.5 \%$, respectively. HOMA-IR and QUICKI indices were calculated by the following formulas:

QUICKI = $1 /$ (log fasting insulin $[\mu \mathrm{iu} / \mathrm{ml}])+\log$ fasting glucose $[\mathrm{mg} / \mathrm{dl}])$

HOMA-IR = FBI $[\mu i \mathrm{iu} / \mathrm{ml}] \times F B S[\mathrm{mg} / \mathrm{dl}] / 405$

\section{Sample Size:}

The sample size was calculated using the 'two mean comparison formula' and one of the similar previous studies ${ }^{(43)}$, considering the cholesterol as the main variable, and errors I and II, the mean difference of cholesterol between the groups, the standard deviation of group 1 and 2 were 0.05 and 0.2 , $17.38,29.34$ and 4.77 respectively.

$\mathrm{n}=\left(\mathrm{Z}_{1-\mathrm{a} / 2}+\mathrm{Z}_{1-\beta}\right)^{2}\left(\mathrm{~S}_{1}{ }^{2}+\mathrm{S}_{2}{ }^{2}\right) /\left(\mu_{1}-\mu_{2}\right)^{2}$ 
The calculated sample size was 23 participants in each group. Considering the anticipation of a $30 \%$ drop-out, the sample size was estimated at 30 participants in each group.

\section{-Data Analysis and Accessibility:}

Data management including entry, security, coding, and storage was performed at this stage. The Kolmogorov-Smirnov, Chi-square, and t-test assessed the normality of continuous variables as well as categorical and continuous baseline characteristics, respectively. Two-way repeated-measure analysis of variance (TWRM-ANOVA) was used to determine time effects and time by treatment interaction effects on all dependent variables. Moreover, TWRM-ANOVA was adjusted for dietary intake of vitamin B12. Also, $95 \%$ confidence interval $(\mathrm{Cl})$ and a P-value $<0.05$ were considered for reporting the measurements. Data analysis was conducted using SPSS16 (statistical package for the social sciences). The main researcher had access to the final dataset and the results were presented by the publication.

\section{Results}

\section{-Participants' characteristics}

According to Figure 1, overall, 680 people were screened based on medical history. Specifically, 82 subjects had the eligibility criteria, of whom 12 declined and 4 could not participate. Also, 66 subjects were randomized, with 3 subjects in the BP group and 3 subjects in the placebo group refusing to participate and as such did not receive the intervention. Thus, the first visit was completed with 60 subjects (bunuim persicum $n=30$; placebo $n=30$ ). Also, 6 subjects could not continue the follow-up stage (for personal reasons, travel and did not take more than $10 \%$ of the intervention supplement; bunuim persicum $n=3$; placebo $n=3$ ). Further, the baseline serum sample of two subjects in the placebo group was not available. Eventually, data analysis was performed on 52 subjects.

The general characteristics and physical activity level of the patients are presented in Table 1. Most of the participants had a similar education, high economic and low physical activity level. Both groups used more than $95 \%$ of the prescribed supplements.

\section{-Changes in dietary intake and blood biomarkers}

The dietary intake of carbohydrates, protein percent and iron in the baseline were higher in the BP group, while the other baseline features were similar in the two groups (Tables 3 ).

The dietary intake of vitamin B12 during the study was higher in the BP group $(P<0.05$, Table 3), while the other dietary intakes were almost similar in the two groups. This significant intake was considered as a confounder in the final analysis model. Within the BP group, the mean difference of TC, TG, HDL, and LDL were not significant $(P>0.05)$. On the other hand, FBS, FBI, BMI, WC, and HOMA-IR reduced, while QUICKI and nesfatin-1 increased significantly $(P<0.05)$. Within the placebo group, the mean differences of FBS, FBI, HOMA-IR, QUICKI, TC, TG, LDL-C, HDL-C and nesfatin-1 were not significant ( $P>0.05)$ (Table 4). 
According to the time by treatment interaction effect in the final analysis model, FBS, HOMA-IR, BMI, and WC declined while QUICKI increased significantly in the BP group in comparison with the placebo group $(\mathrm{P}<0.05)$ (Table 4). In other words, BP in comparison with placebo significantly elevated QUICKI, reduced FBS and HOMA-IR $(P<0.05)$. After adjustment for confounders, the significant changes were similar $(P<0.05)$ with an exception of WC $(P=0.2)$ (Table 4).

\section{-Safety}

Any side effects related to the treatment were reported, and only vomiting was observed in one patient in the BP group in one of his follow-ups.

\section{Discussion}

This was the first time the effects of Bunium Persicum (black caraway) on blood glucose indices, lipid profile and Serum levels of nesfatin-1 in overweight or obese patients with type 2 diabetes mellitus (T2DM) had been assessed. The different clinical usages and the lack of awareness concerning the advantages and disadvantages of Bunium Persicum in patients with T2DM have made it very relevant. According to both unadjusted and adjusted analysis models, consumption of 2,000 mg of BP for 8 weeks caused a significant reduction in FBG, HOMA-IR, BMI and increased QUICKI in the intervention group compared with the placebo group. Furthermore, the decrease in WC was significant in the unadjusted model but not significant in the adjusted model.

Limited human studies have investigated the effect of Bunium Persicum on glucose indices and lipid profiles and according to our knowledge no study has examined the effects of Bunium Persicum on serum levels of nesfatin-1 in these patients. Some results of different studies on the effects of Bunium Persicum or other plants of the Apiaceae family have shown some contradictions are presented below.

The flavonoids, especially quercetin, can increase nesfatin-1 gene expression ${ }^{(44)}$. In our study, Bunium Persicum increased the serum nesfatin-1 significantly in the BP group, however, the increase of nesfatin-1 in the BP group in comparison with the placebo group was not significant. The reasons are likely to be the short time of intervention and lower sample size in the study. Furthermore, Kaempferol is a natural flavonol, a type of flavonoid that can up-regulate the satiety gene NUCB-2/nesfatin-1 which plays an important role in controlling energy balance, reducing body weight and increasing satiety $(13,45-47)$. Nesfatin-1 can produce several activities including suppression of inflammation, lipid mobilization activity, enhancement of antioxidant defense and a regulatory role in glucose homeostasis that may prevent and reduce the complications, development, and progression of T2DM ${ }^{(48-50)}$. Nesfatin-1 mRNA is expressed in white adipose tissue, gastric mucosa and central nervous system (CNS) such as the hypothalamus and brainstem ${ }^{(51-54)}$. However, nesfatin-1 was identified in human plasma and negatively correlated with body mass index ${ }^{(55)}$. 
In several animal studies, caraway (Bunuim Persicum and Carum Carvi) significantly decreased FBS levels $(36,56,57)$. In contrast with our study, the caraway in obese and overweight patients over 12 weeks had no significant effects on FBS (31). This may be attributed to the sample size and form of the supplementation in our intervention. A hypothesis for the possible mechanism of hypoglycemic activity of this plant may be through its main bioactive compounds. The hypoglycemic effect of limonene has been previously reported in diabetic rats by decreasing the activities of gluconeogenic enzymes, increasing the glycolytic enzymes and stimulating insulin secretion in pancreatic $\beta$-cells ${ }^{(58,59)}$. Cumin aldehyde in the Bunium Persicum oilseeds has significant inhibitory activity against the a-glucosidase enzyme that catalyzes the final step in the digestive process of carbohydrates. The inhibitory effect of cumin aldehyde can postpone glucose uptake and reduce hyperglycemia ${ }^{(26)}$. Also, nesfatin-1 can improve glucose indices through many mechanisms such as the enhancement of glucose-induced insulin secretion by promoting ca $2+$ influx through L-type channels $(60,61)$. Thus, the present improvements may be attributed to increased nesfatin-1 levels.

Even though in our study lipid profile was not changed significantly, two human studies demonstrated the improvement of lipid profile by using caraway. The beneficial effects of caraway on lipid profile including LDL, HDL, TG, and cholesterol had been observed in most of the animal models ${ }^{(19,62)}$.

In our study, black caraway significantly reduced body weight, body mass index compared to the placebo group although waist circumference reduction was not significant. This may be attributed to the short time of the intervention in our study. Results in our study are almost consistent with previous studies. Caraway extract supplementation in overweight and obese women over a period of 90 days decreased weight, body mass index, body fat percentage, and waist-to-hip ratio ${ }^{(43)}$. Another human study on the effects of taking the caraway supplement and eight weeks of aerobic exercise showed a significant alteration in the weight and BMI in the supplement-exercise group compared to the other groups (63). The explained mechanisms in the improvement of weight, BMI and WC may be related to the increased levels of serum nesfatin- 1 by BP. Nesfatin-1 can affect the energy homeostasis, decrease appetite and reduce body weight ${ }^{(64-66)}$.

The observed metabolic and clinical response to BP in T2DM patients would make this study relevant. Although BP has some effects on some clinical and metabolic indicators in our study, these effects are small and require further studies with a larger sample size and longer duration and in different diseases.

This study has several strengths in its procedure: To start, there was the first assessment of BP effects in overweight or obese T2DM patients especially by assessing nesfatin-1 levels; second, the double-blinded stratified blocked randomization design; third, assessing dietary intake and physical activity status and adjustment in them and other potential confounders; fourth, considering the control group and fifth, considering multiple eligibility criteria.

However, our study had some limitations. First, the sample size was small, second, the intervention duration was short in order to understand the real effects of bunuim persicum (black caraway) 
supplementation, third, self-reporting of diet and physical activity, fourth, failure to check the bioavailability of BP and measure serum levels of its components, fifth, 24-h food recall is not a good index for assessing the usual food intake sixth, failure to measure body composition and blood pressure, seventh, no assessment of the dietary intake status of the participants during the intervention period and eighth, the effect size was small.

\section{Conclusion}

BP supplementation in overweight or obese T2DM patients showed a significant beneficial effect on serum glucose indices and BMI. Further trials are required to use BP in clinical practice.

\section{Abbreviations}

T2DM: type 2 diabetes mellitus, BP: Bunium Persicum, BMI: body mass index, IPAQ: international physical activity questionnaire, I.C.V injection: Intracerebroventricular injection, TG: triglyceride, ELISA: enzymelinked immunosorbent assay, TWRM-ANOVA: two-way repeated-measures analysis of covariance

\section{Declarations}

-Ethics approval and consent to participate: This trial was approved by the Ethics Committee of Zahedan University of Medical Sciences (Ethical Code: IR.ZAUMS.REC.1397.332). A written informed consent form (in Persian) and informed assent (in Persian) obtained from all patients. Participation was free, and a patient could withdraw at whatever point the person feels he/she was unable to continue. The lifestyle advice was presented free to the patients and there was no bar to receiving the other health care services of the center. Side-effects of Bunium Persicum (Black Caraway) supplement (up to $2 \mathrm{gram} /$ day) have not been reported previously. The personal information of patients was kept secret before and after the study.

-Consent to publish: Not applicable.

-Availability of data and materials: The datasets used and/or analyzed during the current study are available from the corresponding author on a reasonable request.

-Competing Interests: There is no potential conflict of interest to research, authorship, and publication.

-Funding: Funding was supported by the Zahedan University of Medical Sciences. The funding body did not have a role in the design of the study and collection, analysis, interpretation of data and writing the manuscript.

-Authors Contributions: SJM, MS, MDM, and ZM conceived and developed the idea for the paper and revised the manuscript. ASG wrote numerous drafts. ADP contributed to statistical interpretations. All authors read and approved the final manuscript. 
-Acknowledgments: The support of Zahedan University of Medical Sciences and the cooperation of the Bu-Ali hospital of Zahedan and participants are acknowledged.

\section{References}

1. Control CfD, Prevention. National diabetes statistics report, 2017. Atlanta, GA: Centers for Disease Control and Prevention, US Department of Health and Human Services. 2017.

2. Yazdanpanah L, Shahbazian H, Aleali AM, Jahanshahi A, Ghanbari S, Latifi S. Prevalence, awareness and risk factors of diabetes in Ahvaz (South West of Iran). Diabetes \& Metabolic Syndrome: Clinical Research \& Reviews. 2016;10(2):S114-S8.

3. Lovic D, Piperidou A, Zografou I, Grassos H, Pittaras A, Manolis A. The Growing Epidemic of Diabetes Mellitus. Current Vascular Pharmacology. 2020;18(2):104-9.

4. Zheng M, Yang S, Liu Y, He Q, Hu P, editors. A Model for Physical Activity Behavioural Change in Middle Aged and Older People with Type 2 Diabetes. E3S Web of Conferences; 2019: EDP Sciences.

5. Chen G-Y, Li L, Dai F, Li X-J, Xu X-X, Fan J-G. Prevalence of and risk factors for type 2 diabetes mellitus in hyperlipidemia in China. Medical science monitor: international medical journal of experimental and clinical research. 2015;21:2476.

6. Thévenod F. Pathophysiology of diabetes mellitus type 2: roles of obesity, insulin resistance and $\beta$ cell dysfunction. Diabetes and Cancer. 19: Karger Publishers; 2008. p. 1-18.

7. Smitka K, Marešová D. Adipose tissue as an endocrine organ: an update on pro-inflammatory and anti-inflammatory microenvironment. Prague Med Rep. 2015;116(2):87-111.

8. Saldanha J, Carrero J, Lobo J, Stockler-Pinto M, Leal V, Calixto A, et al. The newly identified anorexigenic adipokine nesfatin-1 in hemodialysis patients: are there associations with food intake, body composition and inflammation? Regulatory peptides. 2012;173(1-3):82-5.

9. Ayada C, Toru Ü, Korkut Y. Nesfatin-1 and its effects on different systems. Hippokratia. 2015;19(1):4.

10. Gonzalez R, Kerbel B, Chun A, Unniappan S. Molecular, cellular and physiological evidences for the anorexigenic actions of nesfatin-1 in goldfish. PLoS One. 2010;5(12).

11. Jazayeri-Tehrani SA, Rezayat SM, Mansouri S, Qorbani M, Alavian SM, Daneshi-Maskooni M, et al. Nano-curcumin improves glucose indices, lipids, inflammation, and Nesfatin in overweight and obese patients with non-alcoholic fatty liver disease (NAFLD): a double-blind randomized placebocontrolled clinical trial. Nutrition \& metabolism. 2019;16(1):8.

12. Başar Ö, Akbal E, Köklü S, Koçak E, Tuna Y, Ekiz F, et al. A novel appetite peptide, nesfatin-1 in patients with non-alcoholic fatty liver disease. Scandinavian journal of clinical and laboratory investigation. 2012;72(6):479-83.

13. Oh S, Shimizu H, Satoh T, Okada S, Adachi S, Inoue K, et al. Identification of nesfatin-1 as a satiety molecule in the hypothalamus. Nature. 2006;443(7112):709-12.

14. Li Q-C, Wang H-Y, Chen $X$, Guan H-Z, Jiang Z-Y. Fasting plasma levels of nesfatin-1 in patients with type 1 and type 2 diabetes mellitus and the nutrient-related fluctuation of nesfatin-1 level in normal 
humans. Regulatory peptides. 2010;159(1-3):72-7.

15. Malaguti-Boyle M. Evidence for the effectiveness of clinical nutrition therapy in diabetes mellitus type 2: management in primary care. Journal of the Australian Traditional-Medicine Society. 2016;22(2):74.

16. Odegard PS, Capoccia K. Medication taking and diabetes. The Diabetes Educator. 2007;33(6):101429.

17. Chang Hy, Wallis $\mathrm{M}$, Tiralongo $\mathrm{E}$. Use of complementary and alternative medicine among people living with diabetes: literature review. Journal of advanced nursing. 2007;58(4):307-19.

18. Jabbari M, Daneshfard B, Emtiazy M, Khiveh A, Hashempur MH. Biological effects and clinical applications of dwarf elder (Sambucus ebulus $L$ ): A review. Journal of evidence-based complementary \& alternative medicine. 2017;22(4):996-1001.

19. Haidari F, Seyed-Sadjadi N, Taha-Jalali M, Mohammed-Shahi M. The effect of oral administration of Carum carvi on weight, serum glucose, and lipid profile in streptozotocin-induced diabetic rats. Saudi Med J. 2011;32(7):695-700.

20. Eddouks M, Maghrani M, Lemhadri A, Ouahidi M-L, Jouad H. Ethnopharmacological survey of medicinal plants used for the treatment of diabetes mellitus, hypertension and cardiac diseases in the south-east region of Morocco (Tafilalet). Journal of ethnopharmacology. 2002;82(2-3):97-103.

21. Hajhashemi V, Sajjadi SE, Zomorodkia M. Antinociceptive and anti-inflammatory activities of Bunium persicum essential oil, hydroalcoholic and polyphenolic extracts in animal models. Pharmaceutical biology. 2011;49(2):146-51.

22. Nickavar B, Adeli A, Nickavar A. Analyses of the essential oil from Bunium persicum fruit and its antioxidant constituents. Journal of oleo science. 2014;63(7):741-6.

23. Sharififar F, Yassa N, Mozaffarian V. Bioactivity of major components from the seeds of Bunium persicum (Boiss.) Fedtch. Pakistan journal of pharmaceutical sciences. 2010;23(3).

24. Azizi M, Davareehejad G, Bos R, Woerdenbag HJ, Kayser O, Davareenejad G. The Essential Oil Content and Constituents of Black Zira (Bunium persicum [Boiss.] B. Fedtsch.) during Field

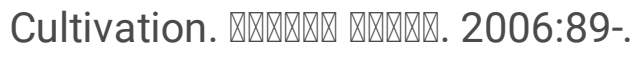

25. Seri A, Khorsand M, Rezaei Z, Hamedi A, Takhshid MA. Inhibitory effect of bunium persicum hydroalcoholic extract on glucose-induced albumin glycation, oxidation, and aggregation in vitro. Iranian journal of medical sciences. 2017;42(4):369.

26. Lee H-S. Cuminaldehyde: aldose reductase and a-glucosidase inhibitor derived from Cuminum cyminum L. seeds. Journal of agricultural and food chemistry. 2005;53(7):2446-50.

27. Patil SB, Takalikar SS, Joglekar MM, Haldavnekar VS, Arvindekar AU. Insulinotropic and $\beta$-cell protective action of cuminaldehyde, cuminol and an inhibitor isolated from Cuminum cyminum in streptozotocin-induced diabetic rats. British journal of nutrition. 2013;110(8):1434-43.

28. Haque MR, Ansari HS. Anti-obesity effect of Arq Zeera and Its main components thymol and cuminaldehyde in high fat diet induced obese rats. Drug research. 2018;68(11):637-47. 
29. Haque M, Ansari S. Aromatic aldehyde compound cuminaldehyde protects nonalcoholic fatty liver disease in rats feeding high fat diet. Human \& experimental toxicology. 2019;38(7):823-32.

30. Khaksari M, Ahmadi M, Najafipour $\mathrm{H}$, Shahrokhi N. Effect of Bunium persicum aqueous extract plus endurance exercise on cardiorespiratory capacity and serum lipid profile. Avicenna journal of phytomedicine. 2014;4(2):118.

31. Kazemipoor M, Cordell GA. Clinical effects of caraway, a traditional medicine for weight loss. Evidence-Based Validation of Herbal Medicine: Elsevier; 2015. p. 339-62.

32. Ghorbani S, Alizadeh R, Moradi L. The effect of high intensity interval training along with consumption of caraway seeds (Carum carvi L.) on liver enzymes, lipid profile, and blood glucose in obese and overweight women. Ebnesina. 2017;19(2):12-20.

33. Hassanzad Azar H, Taami B, Aminzare M, Daneshamooz S. Bunium persicum (Boiss.) B. Fedtsch: An overview on Phytochemistry, Therapeutic uses and its application in the food industry. Journal of Applied Pharmaceutical Science. 2018;8(10):150-8.

34. Moubarz G, Taha MM, Mahdy-Abdallah H. Antioxidant effect of Carum carvi on the immune status of streptozotocin-induced diabetic rats infected with Staphylococcus aureus. World Applied Sciences Journal. 2014;30(1):63-9.

35. Kazemipoor M, Hamzah S, Hajifaraji M, Radzi CWJBWM, Cordell GA. Slimming and AppetiteSuppressing Effects of Caraway Aqueous Extract as a Natural Therapy in Physically Active Women. Phytotherapy Research. 2016;30(6):981-7.

36. Sadjadi NS, Shahi MM, Jalali M-T, Haidari F. Short-Term Caraway Extract Administration Improves Cardiovascular Disease Risk Markers in Streptozotocin-Induced Diabetic Rats: A Dose-Response Study. Journal of Dietary Supplements. 2014;11(1):30-9.

37. Mirzaei K, Hossein-nezhad A, Keshavarz SA, Koohdani F, Eshraghian MR, Saboor-Yaraghi AA, et al. Association of nesfatin-1 level with body composition, dietary intake and resting metabolic rate in obese and morbid obese subjects. Diabetes \& Metabolic Syndrome: Clinical Research \& Reviews. 2015;9(4):292-8.

38. Zare R, Heshmati F, Fallahzadeh H, Nadjarzadeh A. Effect of cumin powder on body composition and lipid profile in overweight and obese women. Complementary therapies in clinical practice. 2014;20(4):297-301.

39. JAZAYERI S, NOURI M, POUREBRAHIM R, FAKHRZADEH H, ARDESHIR LARIJANI MB. FOOD AND NUTRIENT INTAKES AMONG 20-60 AGED INHABITANTS OF TEHRAN UNIVERSITY OF MEDICAL SCIENCES POPULATION LAB REGION. JOURNAL OF DIABETES AND METABOLIC DISORDERS. 2004;3(Supplement 1 (MONICA PROJRCT)):-.

40. Ghafarpour M, Houshiar-Rad A, Kianfar H, Ghaffarpour M. The manual for household measures, cooking yields factors and edible portion of food. 1999.

41. Baghiani-Moghaddam M, Bakhtari-Aghdam F, Asghari-Jafarabadi M, Allahverdipour $H$, Saeed Dabagh-Nikookheslat $S$, Nourizadeh R. Comparing the results of pedometer-based data and International Physical Activity Questionnaire (IPAQ). J Health Syst Res. 2013;9(6):605-12. 
42. Vahedian-Shahroodi M, Tehrani H, Dogonchi M, Lael-monfared E. The Effectiveness of Physical Activity Training on Depersonalization and lack of accomplishment of Employees. Iranian Journal of Health Education and Health Promotion. 2015;3(2):116-24.

43. Kazemipoor M, Hajifaraji M, Haerian BS, Mosaddegh MH, Cordell GA. Antiobesity effect of caraway extract on overweight and obese women: a randomized, triple-blind, placebo-controlled clinical trial. Evidence-Based Complementary and Alternative Medicine. 2013;2013.

44. Khorchani MJ, Zal F, Neisy A. The phytoestrogen, quercetin, in serum, uterus and ovary as a potential treatment for dehydroepiandrosterone-induced polycystic ovary syndrome in the rat. Reproduction, Fertility and Development. 2020;32(3):313-21.

45. Hossain AM, Brennan MA, Guo X, Zeng X-A, Brennan CS. Cellular biological activity and regulation of gene expression of antioxidant dietary fibre fraction isolated from blackcurrant incorporated in the wholemeal cereals cookies. Food Chemistry. 2020;312:125829.

46. García-Galiano D, Pineda R, Ilhan T, Castellano J, Ruiz-Pino F, Sánchez-Garrido M, et al. Cellular distribution, regulated expression, and functional role of the anorexigenic peptide, NUCB2/nesfatin-1, in the testis. Endocrinology. 2012;153(4):1959-71.

47. Holland TM, Agarwal P, Wang Y, Leurgans SE, Bennett DA, Booth SL, et al. Dietary flavonols and risk of Alzheimer dementia. Neurology. 2020.

48. Jiang L, Xu K, Li J, Zhou X, Xu L, Wu Z, et al. Nesfatin-1 suppresses interleukin-1ß-induced inflammation, apoptosis, and cartilage matrix destruction in chondrocytes and ameliorates osteoarthritis in rats. Aging (Albany NY). 2020;12(2):1760.

49. Liu Y, Chen X, Qu Y, Song L, Lin Q, Li M, et al. Central nesfatin-1 activates lipid mobilization in adipose tissue and fatty acid oxidation in muscle via the sympathetic nervous system. BioFactors. 2020.

50. Li Z, Gao L, Tang H, Yin Y, Xiang X, Li Y, et al. Peripheral effects of nesfatin-1 on glucose homeostasis. PloS one. 2013;8(8).

51. SHimizu H, OH S, Okada S, Mori M. Nesfatin-1: an overview and future clinical application. Endocrine journal. 2009;56(4):537-43.

52. Stengel A, Goebel M, Yakubov I, Wang L, Witcher D, Coskun T, et al. Identification and characterization of nesfatin-1 immunoreactivity in endocrine cell types of the rat gastric oxyntic mucosa. Endocrinology. 2009;150(1):232-8.

53. Ramanjaneya M, Chen J, Brown JE, Tripathi G, Hallschmid M, Patel S, et al. Identification of nesfatin1 in human and murine adipose tissue: a novel depot-specific adipokine with increased levels in obesity. Endocrinology. 2010;151(7):3169-80.

54. Kim J, Chung Y, Kim H, Im E, Lee H, Yang $H$. The tissue distribution of nesfatin-1/NUCB2 in mouse. Development \& reproduction. 2014;18(4):301.

55. Tsuchiya T, Shimizu H, Yamada M, Osaki A, Oh-I S, Ariyama Y, et al. Fasting concentrations of nesfatin-1 are negatively correlated with body mass index in non-obese males. Clinical Endocrinology. 2010;73(4):484-90. 
56. Eidi A, Eidi M, Haeri Rohani A, Basati F. Hypoglycemic effect of ethanolic extract of Carum carvi L. seeds in normal and streptozotocin-induced diabetic rats. Journal of Medicinal Plants. 2010;3(35):106-13.

57. Giancarlo § S, Rosa § LM, Nadjafi F, Francesco M. Hypoglycaemic activity of two spices extracts: Rhus coriaria L. and Bunium persicum Boiss. Natural product research. 2006;20(9):882-6.

58. Murali R, Saravanan R. Antidiabetic effect of d-limonene, a monoterpene in streptozotocin-induced diabetic rats. Biomedicine \& Preventive Nutrition. 2012;2(4):269-75.

59. Conforti F, Statti GA, Tundis R, Loizzo MR, Menichini F. In vitro activities of Citrus medica L. cv. Diamante (Diamante citron) relevant to treatment of diabetes and Alzheimer's disease. Phytotherapy Research: An International Journal Devoted to Pharmacological and Toxicological Evaluation of Natural Product Derivatives. 2007;21(5):427-33.

60. Nakata M, Manaka K, Yamamoto S, Mori M, Yada T. Nesfatin-1 enhances glucose-induced insulin secretion by promoting $\mathrm{Ca} 2+$ influx through $\mathrm{L}$-type channels in mouse islet $\beta$-cells. Endocrine journal. 2011:1102080532-.

61. Öztürk Özkan G. Effects of Nesfatin-1 on Food Intake and Hyperglycemia. Journal of the American College of Nutrition. 2019:1-7.

62. Saghir MR, Sadiq S, Nayak S, Tahir MU. Hypolipidemic effect of aqueous extract of Carum carvi (black Zeera) seeds in diet induced hyperlipidemic rats. Pakistan Journal of Pharmaceutical Sciences. 2012;25(2).

63. Mohammadkhani PG, Irandoust K, Taheri M, Mirmoezzi M, Baić M. Effects of eight weeks of aerobic exercise and taking caraway supplement on C-reactive protein and sleep quality in obese women. Biological Rhythm Research. 2019:1-9.

64. Tsuchiya T, Shimizu H, Yamada M, Osaki A, Oh-I S, Ariyama Y, et al. Fasting concentrations of nesfatin- 1 are negatively correlated with body mass index in non-obese males. Clinical endocrinology. 2010;73(4):484-90.

65. Abaci A, Catli G, Anik A, Kume T, Bober E. The relation of serum nesfatin-1 level with metabolic and clinical parameters in obese and healthy children. Pediatric diabetes. 2013;14(3):189-95.

66. Dong J, Xu H, Wang P-f, Cai G-j, Song H-f, Wang C-c, et al. Nesfatin-1 stimulates fatty-acid oxidation by activating AMP-activated protein kinase in STZ-induced type 2 diabetic mice. PLoS One. 2013;8(12):e83397.

\section{Tables}

Table 1. General characteristics and physical activity of overweight or obese patients with type 2 diabetes mellitus (T2DM) 


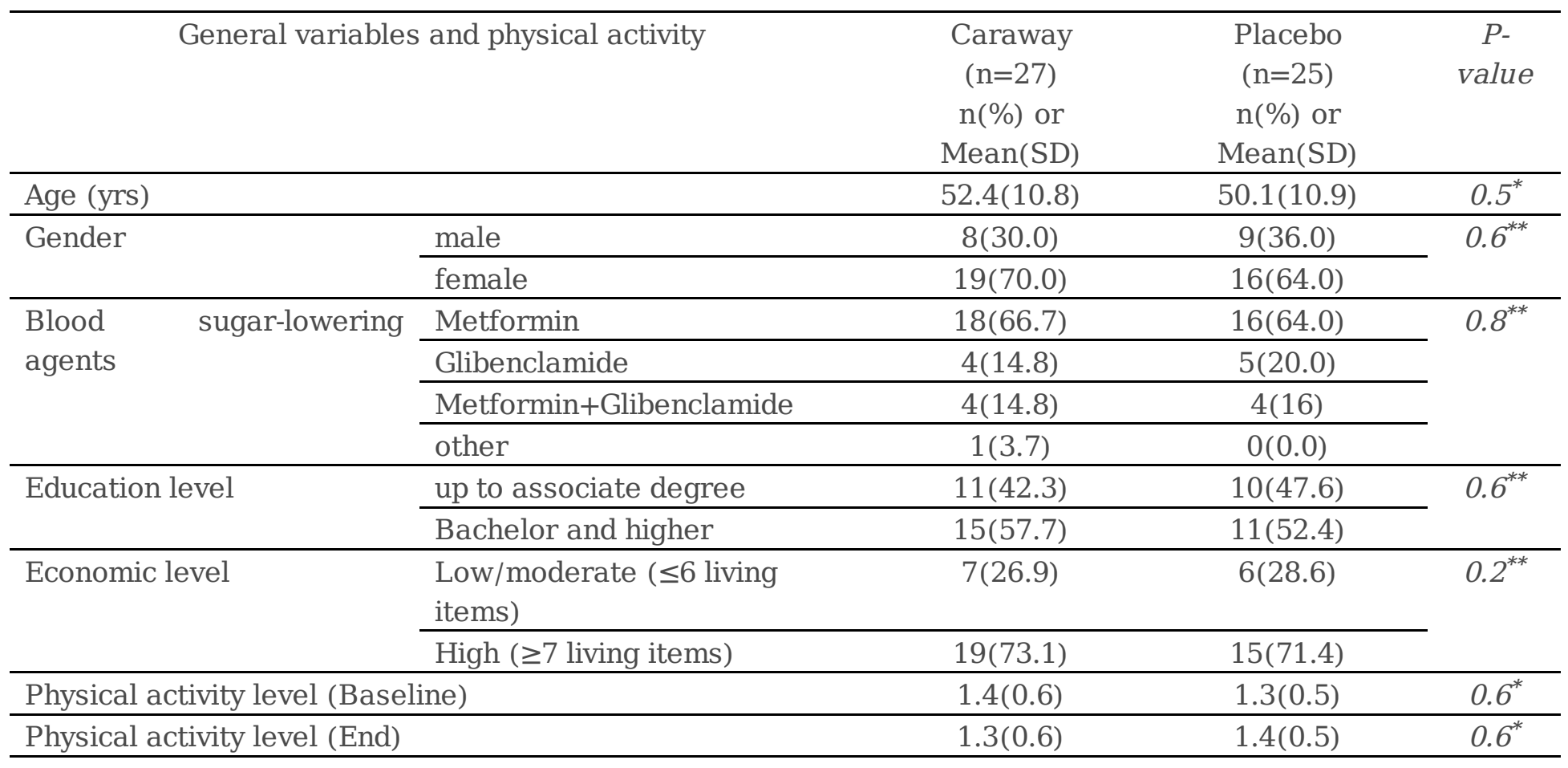

*t-test, $*^{*}$ Chi-square

Table 2. Comparison of baseline mean for BMI and serum nesfatin-1, glucose indices, and lipid profile in overweight or obese patients with type 2 diabetes mellitus (T2DM)

\begin{tabular}{|c|c|c|c|}
\hline Baseline Dependent Variables & $\begin{array}{c}\text { Caraway } \\
(\mathrm{n}=27) \\
\mathrm{n}(\%) \text { or Mean(SD) }\end{array}$ & $\begin{array}{c}\text { Placebo } \\
(\mathrm{n}=25) \\
\mathrm{n}(\%) \text { or Mean(SD) }\end{array}$ & $P$-value ${ }^{*}$ \\
\hline $\mathrm{BMI}(\mathrm{kg} / \mathrm{m} 2)$ & $28.8(3.8)$ & $29.2(3.3)$ & 0.7 \\
\hline $\mathrm{WC}(\mathrm{cm})$ & $100.32(7.06)$ & $100.35(8.45)$ & 0.9 \\
\hline FBS (mg/dl) & $175.3(17.6)$ & $174.0(17.9)$ & 0.9 \\
\hline FBI $(\mu \mathrm{IU} / \mathrm{ml})$ & $9.4(1.6)$ & $11.6(1.9)$ & 0.3 \\
\hline HOMA-IR (score) & $4.2(3.0)$ & $5.0(3.7)$ & 0.5 \\
\hline QUICKI (score) & $0.450(0.004)$ & $0.445(0.002)$ & 0.6 \\
\hline Nesfatin-1 (ng/ml) & $4.4(1.6)$ & $5.5(2.1)$ & 0.07 \\
\hline TC (mg/dl) & $159.0(36.0)$ & $152.6(48)$ & 0.6 \\
\hline TG (mg/dl) & $163.3(117.1)$ & $164.2(82.4)$ & 0.9 \\
\hline LDL-C (mg/dl) & $81.3(27.6)$ & $83.3(29.6)$ & 0.8 \\
\hline HDL-C (mg/dl) & $45.0(12.0)$ & $43.0(7.6)$ & 0.5 \\
\hline
\end{tabular}

*t-test; BMI: body mass index, WC: waist circumference, HOMA-IR: homeostasis model assessment-insulin resistance, QUICKI: quantitative insulin sensitivity check index, FBS: fasting blood sugar, FBI: fasting blood 
insulin, TC: total cholesterol, TG: triglyceride, HDL-C: high-density lipoprotein cholesterol, LDL-C: low-density lipoprotein-cholesterol

Table 3. Mean of dietary intakes during the study on overweight or obese patients with type 2 diabetes mellitus (T2DM)

\begin{tabular}{|c|c|c|c|}
\hline Dietary intakes during the study & $\begin{array}{c}\text { Bunium persicum }(\mathrm{n}=27) \\
\text { Mean }(95 \% \mathrm{CI})\end{array}$ & $\begin{array}{l}\text { Placebo }(\mathrm{n}=25) \\
\text { Mean }(95 \% \mathrm{CI})\end{array}$ & $P$-value \\
\hline Energy (kcal) & 1982.6(1951, 2014.2) & 1799.3(1793.4, 1805.3) & 0.45 \\
\hline Protein $(\mathrm{g})$ & 72.1(71.6, 72.6) & 77.8(78.9, 76.8) & 0.24 \\
\hline Protein (\%) & $14.4(14.5,14.3)$ & $17.3(17.5,17.2)$ & 0.76 \\
\hline Carbohydrate $(\mathrm{g})$ & $274.6(268.6,280.7)$ & $227.0(230.7,223.3)$ & 0.27 \\
\hline Carbohydrate (\%) & $54.8(54.5,55.1)$ & $49.6(50.4,48.8)$ & 0.25 \\
\hline Fat $(\mathrm{g})$ & $69.1(69.0,69.3)$ & $66.5(65.3,67.8)$ & 0.55 \\
\hline Fat $(\%)$ & $30.8(31,30.6)$ & $33.0(32.0,34.1)$ & 0.17 \\
\hline Cholesterol (mg) & $133.4(123.5,143.3)$ & $130.9(132.3,129.5)$ & 0.11 \\
\hline Saturated fat $(\mathrm{g})$ & 20.3(19.6, 21.1) & $16.1(15.9,16.3)$ & 0.69 \\
\hline Monounsaturated fatty acid (g) & $25.3(26.9,23.7)$ & $24.4(25.0,23.9)$ & 0.42 \\
\hline Polyunsaturated fatty acid (g) & $17.0(16.4,17.6)$ & $17.8(17.7,18.0)$ & 0.63 \\
\hline Vitamin A [RAE] $(\mu \mathrm{g})$ & 806.2(884.3, 728.2) & $676(752.7,599.3)$ & 0.99 \\
\hline Vitamin C (mg) & $136.4(123.3,149.5)$ & $125.4(118.2,132.6)$ & 0.59 \\
\hline Potassium & $2708.6(2625.0,2792.3)$ & $2588.1(2540.4,2635.8)$ & 0.81 \\
\hline Calcium (mg) & 823.4(837.1, 809.8) & 911.4(934.2, 889.4) & 0.88 \\
\hline Iron (mg) & $19.4(19.1,19.7)$ & $15.2(15.2,15.3)$ & 0.40 \\
\hline Vitamin D ( $\mu \mathrm{g})$ & $0.6(0.5,0.7)$ & $0.5(0.4,0.6)$ & 0.81 \\
\hline Vitamin E (mg) & $17.5(19.8,15.3)$ & $16.0(16.6,15.4)$ & 0.18 \\
\hline Vitamin B1 (mg) & $1.9(2.1,1.7)$ & $1.8(1.9,1.8)$ & 0.20 \\
\hline Vitamin B2 (mg) & $1.8(1.9,1.7)$ & $1.8(1.9,1.7)$ & 0.88 \\
\hline Vitamin B3 (mg) & $23.3(23.9,21.7)$ & $25.7(25.6,25.9)$ & 0.33 \\
\hline Vitamin B6 (mg) & $1.7(2.5,2.4)$ & $2.8(3.3,2.4)$ & 0.37 \\
\hline Folate (DFE) ( $\mu \mathrm{g})$ & $143.7(138.3,149.2)$ & $144.7(147.5,141.9)$ & 0.51 \\
\hline Vitamin B12 ( $\mu \mathrm{g})$ & $2.4(2.3,2.5)$ & $2.2(2.4,2.0)$ & 0.03 \\
\hline Vitamin K ( $\mu \mathrm{g})$ & $182.0(129.3,234.7)$ & $154.9(106.8,203.0)$ & 0.91 \\
\hline Zinc (mg) & 9.5(9.5, 9.6) & 8.6(8.4, 8.8) & 0.70 \\
\hline Selenium $(\mu \mathrm{g})$ & $33.1(32.2,34.1)$ & $39.2(39.0,39.4)$ & 0.82 \\
\hline Total fiber $(\mathrm{g})$ & $4.7(4.4,5)$ & $4.1(3.8,4.5)$ & 0.42 \\
\hline
\end{tabular}

*Two way repeated measures-ANOVA (TWRM-ANOVA)

Table 4. The changes in BMI, WC, serum nesfatin-1, glucose indices, and lipid profile in overweight or obese patients with type 2 diabetes mellitus (T2DM) 


\begin{tabular}{|c|c|c|c|c|c|c|c|c|}
\hline \multirow[t]{2}{*}{ Variables } & \multirow[t]{2}{*}{ Supplement } & \multirow{2}{*}{$\begin{array}{c}\text { Baseline } \\
\text { Mean }\end{array}$} & \multirow{2}{*}{$\begin{array}{l}\text { End } \\
\text { Mean }\end{array}$} & \multirow{2}{*}{$\begin{array}{c}P- \\
\text { value }^{\$}\end{array}$} & \multirow{2}{*}{$\begin{array}{c}\text { Mean } \\
\text { Changes } \\
(95 \% \text { CI })\end{array}$} & \multicolumn{3}{|c|}{$P$-value } \\
\hline & & & & & & Time & Treatment & Interaction \\
\hline \multirow[t]{2}{*}{ BMI } & $\begin{array}{c}\text { Caraway } \\
(\mathrm{n}=27)\end{array}$ & $28.8(3.8)$ & $28.3(4.0)$ & 0.003 & $\begin{array}{c}-0.5 \\
(0.2,0.7) \\
\end{array}$ & 0.4 & 0.5 & 0.02 \\
\hline & $\begin{array}{c}\text { Placebo } \\
(\mathrm{n}=25)\end{array}$ & $29.2(3.3)$ & $29.4(3.3)$ & 0.4 & $\begin{array}{c}0.2 \\
(-.8,0.3)\end{array}$ & 0.8 & 0.6 & 0.04 \\
\hline \multirow[t]{2}{*}{ WC (cm) } & $\begin{array}{c}\text { Caraway } \\
(\mathrm{n}=27)\end{array}$ & 100.3(7.0) & $99.0(7.4)$ & 0.002 & $\begin{array}{c}-1.3 \\
(0.5,2.0)\end{array}$ & 0.013 & 0.8 & 0.04 \\
\hline & $\begin{array}{c}\text { Placebo } \\
(n=25)\end{array}$ & $100.3(8.4)$ & $100.2(8.3)$ & 0.7 & $\begin{array}{c}-0.1 \\
(-0.7,0.9)\end{array}$ & 0.1 & 0.6 & 0.2 \\
\hline \multirow[t]{2}{*}{ FBS (mg/dl) } & $\begin{array}{c}\text { Caraway } \\
(\mathrm{n}=27)\end{array}$ & 175.4(69.9) & 142.6(53.8) & 0.002 & $\begin{array}{r}-32.8 \\
(11.9 \\
51.2) \\
\end{array}$ & 0.036 & 0.3 & 0.005 \\
\hline & $\begin{array}{c}\text { Placebo } \\
(n=25)\end{array}$ & $174.0(52.3)$ & $178.9(73.5)$ & 0.6 & $\begin{array}{c}4.9 \\
(-22.7 \\
12.9) \\
\end{array}$ & 0.2 & 0.8 & 0.02 \\
\hline \multirow[t]{2}{*}{ FBI $(\mu \mathrm{IU} / \mathrm{ml})$} & $\begin{array}{c}\text { Caraway } \\
(\mathrm{n}=27)\end{array}$ & $9.4(6.8)$ & $5.6(2.5)$ & 0.03 & $\begin{array}{c}-3.8 \\
(0.3,7.3) \\
\end{array}$ & 0.245 & 0.006 & 0.15 \\
\hline & $\begin{array}{c}\text { Placebo } \\
(\mathrm{n}=25)\end{array}$ & $11.6(7.5)$ & $12.0(9.0)$ & 0.9 & $\begin{array}{c}0.4 \\
(-5.1,5.3) \\
\end{array}$ & 0.140 & 0.01 & 0.05 \\
\hline \multirow[t]{2}{*}{ HOMA-IR } & $\begin{array}{c}\text { Caraway } \\
(\mathrm{n}=27)\end{array}$ & $4.2(3.7)$ & $2.3(1.3)$ & 0.041 & $\begin{array}{c}-1.9 \\
(0.9,3.8) \\
\end{array}$ & 0.181 & 0.009 & 0.047 \\
\hline & $\begin{array}{c}\text { Placebo } \\
(\mathrm{n}=25)\end{array}$ & $5.0(3.1)$ & $5.2(4.7)$ & 0.87 & $\begin{array}{c}0.2 \\
(-2.5,2.1)\end{array}$ & 0.173 & 0.034 & 0.018 \\
\hline \multirow[t]{2}{*}{ QUICKI } & $\begin{array}{c}\text { Caraway } \\
(\mathrm{n}=27)\end{array}$ & $0.450(0.03)$ & $0.47(0.03)$ & 0.006 & $\begin{array}{c}0.02 \\
(-.03,0.0) \\
\end{array}$ & 0.014 & 0.128 & 0.035 \\
\hline & $\begin{array}{c}\text { Placebo } \\
(\mathrm{n}=25)\end{array}$ & $0.445(0.02)$ & $0.446(0.03)$ & 0.761 & $\begin{array}{c}0.01 \\
(-.04,0.1)\end{array}$ & 0.050 & 0.4 & 0.054 \\
\hline \multirow[t]{2}{*}{$\mathrm{TC}(\mathrm{mg} / \mathrm{dl})$} & $\begin{array}{c}\text { Caraway } \\
(\mathrm{n}=27)\end{array}$ & $159.0(36.8)$ & $159.5(37.1)$ & 0.942 & $\begin{array}{c}0.5 \\
(-13.3 \\
12.4) \\
\end{array}$ & 0.4 & 0.8 & 0.5 \\
\hline & $\begin{array}{c}\text { Placebo } \\
(\mathrm{n}=25)\end{array}$ & 152.6(49.0) & $159.9(45.2)$ & 0.395 & $\begin{array}{c}7.3 \\
(-24.9 \\
10.3) \\
\end{array}$ & 0.8 & 0.6 & 0.9 \\
\hline \multirow[t]{2}{*}{ TG (mg/dl) } & $\begin{array}{c}\text { Caraway } \\
(\mathrm{n}=27)\end{array}$ & $163.3(117.2)$ & $175.3(121.4)$ & 0.389 & $\begin{array}{c}-12.0 \\
(-39.9 \\
16.1) \\
\end{array}$ & 0.1 & 0.9 & 0.8 \\
\hline & $\begin{array}{c}\text { Placebo } \\
(\mathrm{n}=25)\end{array}$ & $164.2(82.4)$ & $179.3(100.4)$ & 0.189 & $\begin{array}{c}15.1 \\
(-38.1,8.0)\end{array}$ & 0.3 & 0.9 & 0.8 \\
\hline \multirow[t]{2}{*}{$\begin{array}{l}\text { LDL-C } \\
(\mathrm{mg} / \mathrm{dl})\end{array}$} & $\begin{array}{c}\text { Caraway } \\
(\mathrm{n}=27)\end{array}$ & $81.3(27.6)$ & $82.6(27.7)$ & 0.842 & $\begin{array}{c}1.3 \\
(-13.7 \\
11.3) \\
\end{array}$ & 0.6 & 0.9 & 0.4 \\
\hline & $\begin{array}{c}\text { Placebo } \\
(n=25)\end{array}$ & 83.3(29.6) & $77.8(39.3)$ & 0.422 & $\begin{array}{c}-5.5 \\
(-8.5,19.5)\end{array}$ & 0.9 & 0.4 & 0.1 \\
\hline \multirow[t]{2}{*}{$\begin{array}{l}\text { HDL-C } \\
(\mathrm{mg} / \mathrm{dl})\end{array}$} & $\begin{array}{c}\text { Caraway } \\
(\mathrm{n}=27)\end{array}$ & $45.0(12.0)$ & $44.2(11.2)$ & 0.520 & $\begin{array}{c}-0.8 \\
(-1.6,3.2) \\
\end{array}$ & 0.9 & 0.7 & 0.3 \\
\hline & $\begin{array}{c}\text { Placebo } \\
(\mathrm{n}=25)\end{array}$ & $43.0(7.6)$ & $44.0(9.2)$ & 0.518 & $\begin{array}{c}1.0 \\
(-4.3,2.3)\end{array}$ & 0.7 & 0.8 & 0.3 \\
\hline
\end{tabular}




\begin{tabular}{|c|c|c|c|c|c|c|c|c|}
\hline \multirow[t]{2}{*}{$\begin{array}{l}\text { Nesfatin-1 } \\
(\mathrm{ng} / \mathrm{ml})\end{array}$} & $\begin{array}{c}\text { Caraway } \\
(\mathrm{n}=27)\end{array}$ & $4.4(1.6)$ & $6.1(3.4)$ & 0.021 & $\begin{array}{c}1.7 \\
(-3.2,0.3)\end{array}$ & 0.01 & 0.3 & 0.59 \\
\hline & $\begin{array}{c}\text { Placebo } \\
(\mathrm{n}=25)\end{array}$ & $5.5(2.1)$ & $6.6(3.9)$ & 0.168 & $\begin{array}{c}1.1 \\
(-2.9,0.5) \\
\end{array}$ & 0.2 & 0.7 & 0.8 \\
\hline
\end{tabular}

\$Paired t-test; \#Two way repeated measures-ANOVA (TWRM-ANOVA), top row P-value: unadjusted; bottom row $\mathrm{P}_{\text {-value: }}$ adjusted for vitamins B12 dietary intake

BMI: body mass index, WC: waist circumference, HOMA-IR: homeostasis model assessment-insulin resistance, QUICKI: quantitative insulin sensitivity check index, FBS: fasting blood sugar, FBI: fasting blood insulin, TC: total cholesterol, TG: triglyceride, HDL-C: high-density lipoprotein cholesterol, LDL-C: low-density lipoproteincholesterol

\section{Figures}

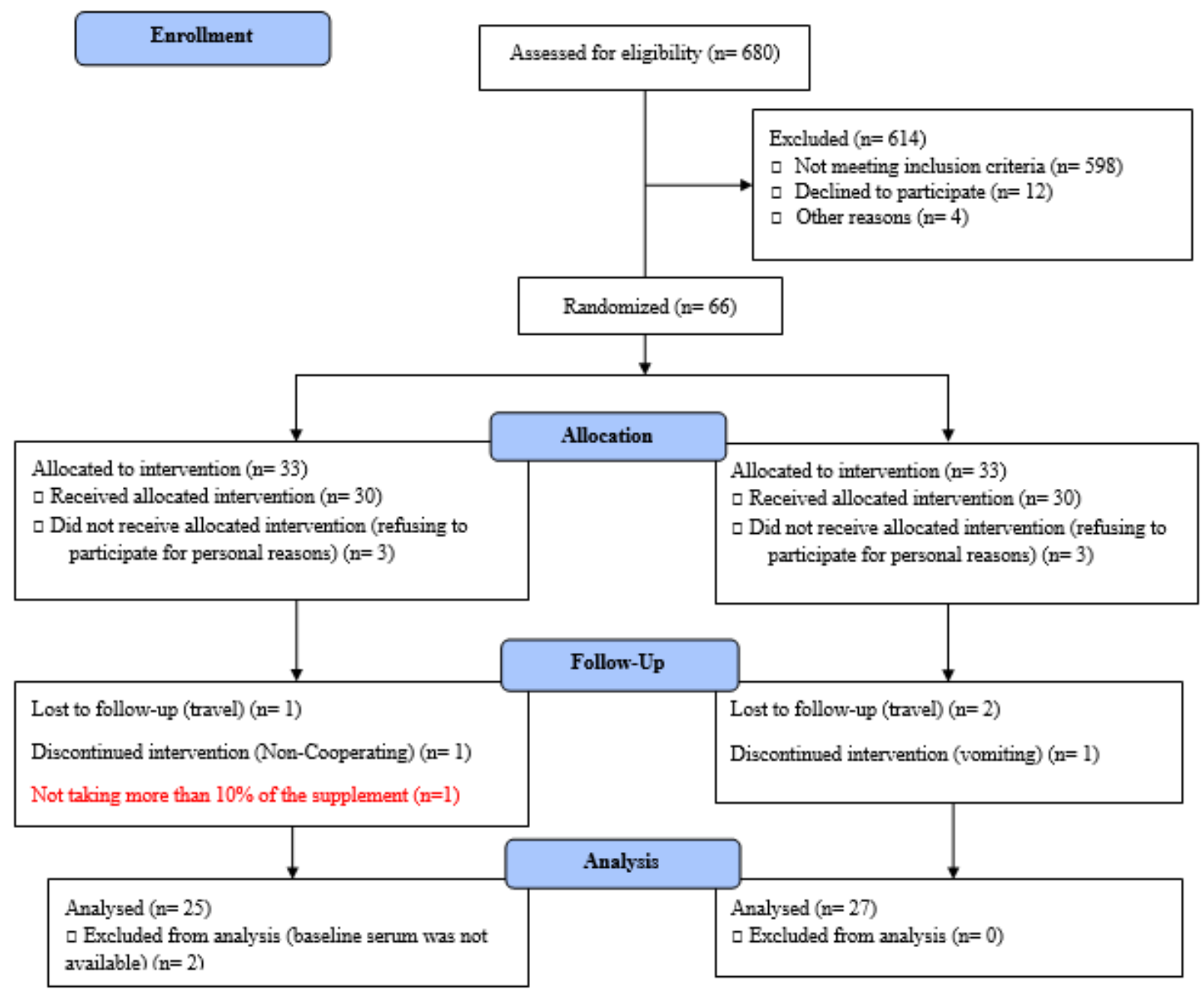

\section{Figure 1}

Flow chart of the study participants 